\title{
Application of different molecular markers in biotechnology
}

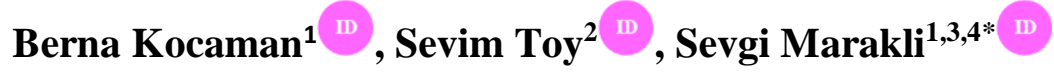 \\ ${ }^{1}$ Department of Biotechnology, Institution of Science, Amasya University, Amasya/Turkey \\ ${ }^{2}$ Department of Biology, Institution of Science, Amasya University, Amasya/Turkey \\ ${ }^{3}$ Department of Medical Services and Techniques, Sabuncuoglu Serefeddin Health Services \\ Vocational School, Amasya University/Turkey \\ ${ }^{4}$ Amasya University, Central Research Laboratory, Amasya/Turkey
}

\begin{abstract}
Several molecular markers have been developed to explore genetic diversity, resistance against biotic/abiotic stress, disease, biomarker and evolutionary relationships in different genomes. These markers could be classified as sequence, hybridisation, PCR and retrotransposon based techniques. In this study, procedure and applications of AFLP (Amplified Fragment Length Polymorphism), ITS (Internal Transcribed Spacer), IRAP (Inter Retrotransposon Amplified Polymorphism), SSR (Simple Sequence Repeats), VNTR (Variable Number Tandem Repeats), SNP (single nucleotide polymorphism), CAPS (Cleaved Amplified Polymorphic Sequences), SCoT (Start Codon Targeted Polymorphism), SSCP (Single Strand Conformational Polymorphism) markers in plant, animal and human genomes were discussed.
\end{abstract}

\section{Introduction}

Markers are properties that could be used to distinguish intra- and/or inter-populations. When compare to morphological markers, molecular markers are more useful, more robust and independent of environmental conditions. Moreover, the strength of these markers has been increased with advances in next-generation sequencing technologies (Grover and Sharma, 2016; Nadeem et al., 2018). Many studies are using these markers in different genomes. However, plant genomes are mainly investigated to analyse genetic diversity by using these markers. Here, we present a detailed procedure and application of various molecular marker techniques in animal and human in addition to plant genomes.

\footnotetext{
${ }^{1}$ Correspondence: sevgi.marakli@amasya.edu.tr
} 


\section{AFLP (Amplified Fragment Length Polymorphism)}

AFLP is one of the PCR-based molecular marker technologies using DNA fragments after digestion with restriction enzymes and compares fingerprints to analyse differences in DNA sequences (Figure 1). The advantage of this method is as follows: no prior information about target genome, high reproducibility and sensitivity. AFLP technique has been used for genetic diversity within and between species, genetic map and evolutionary relationships. Moreover, transcriptomic variations and epigenetic studies such as DNA methylation are also analysed by using this technique (Paun and Schönswetter, 2012).

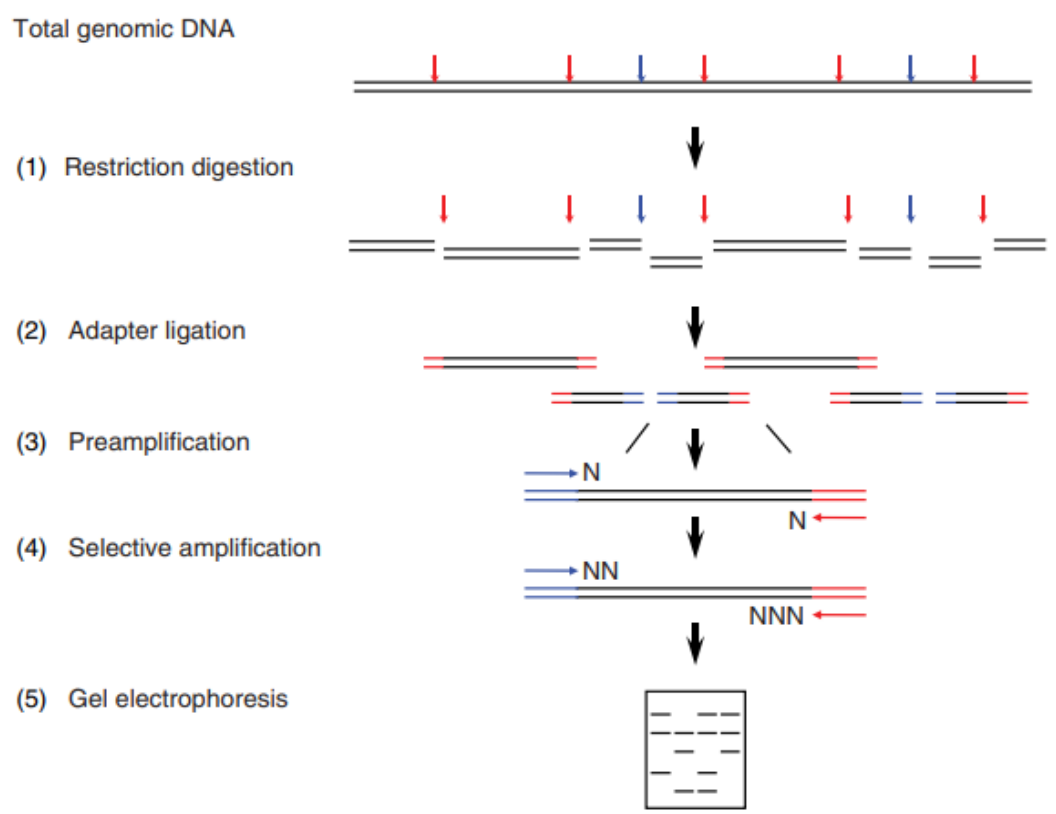

Figure 1. Procedure of AFLP molecular marker. 1. Genomic DNA is digested with combination of EcoRI (blue) and MseI (red) restriction enzymes. 2. EcoRI- (blue) and MseI (red)- specific adapters are ligated to the fragment ends. 3. In pre-amplification step; primersspecific to adapter sequences are used to amplification of fragments. 4. In selective PCR amplification step, selective nucleotides are added to EcoRI and MseI primers. 5. Amplification products are analysed by using denaturing polyacrylamide gels (Vuylsteke et al., 2007)

There are numerous reports to identify polymorphisms among plants via AFLP molecular marker. One of them was carried out by Moya-Hernández et al. (2018). They performed comparative analyses related to genetic diversity of $C$. ficifolia found in some regions of Mexico, reporting a total of 195 bands with $24.6 \%$ polymorphism. Similar to this study, 
Ovesna et al. (2018) used AFLP markers to investigate diversity in a different plant, $S$. sonchifolius. They found higher polymorphism ratio (97.3\%) among plants and reported that this ratio much higher than previous studies.

In some studies, molecular marker combinations have been used to better understand efficiency of markers to investigate polymorphism and comparison the results. Cao et al. (2019) performed one of these studies by using Simple Sequence Repeat (SSR) and (AFLP) markers. They investigated genetic diversity of Pyrus pyrifolia var. Nakai. As a result of SSR, AFLP and SSR+AFLP analyses, they observed rich genetic diversity in Nakai varieties. Similarly, Hadipour et al. (2020) also analysed AFLP and ISSR primer combinations in 67 P.bracteatum genotypes. Among populations, 52\% for ISSR and $48 \%$ for AFLP polymorphism ratios were detected.

\section{ITS (Internal Transcribed Spacer)}

Ribosomal RNA gene and spacer regions have provided phylogenetic knowledge in prokaryotes and eukaryotes. Ribosomal DNA consists of coding regions (18S, 5.8S and 28S) together with two ITS regions and one NTS (non-transcribed spacer) (Wei et al., 2006) (Figure 2). ITS is a degraded region during maturation in ribosomal transcript.

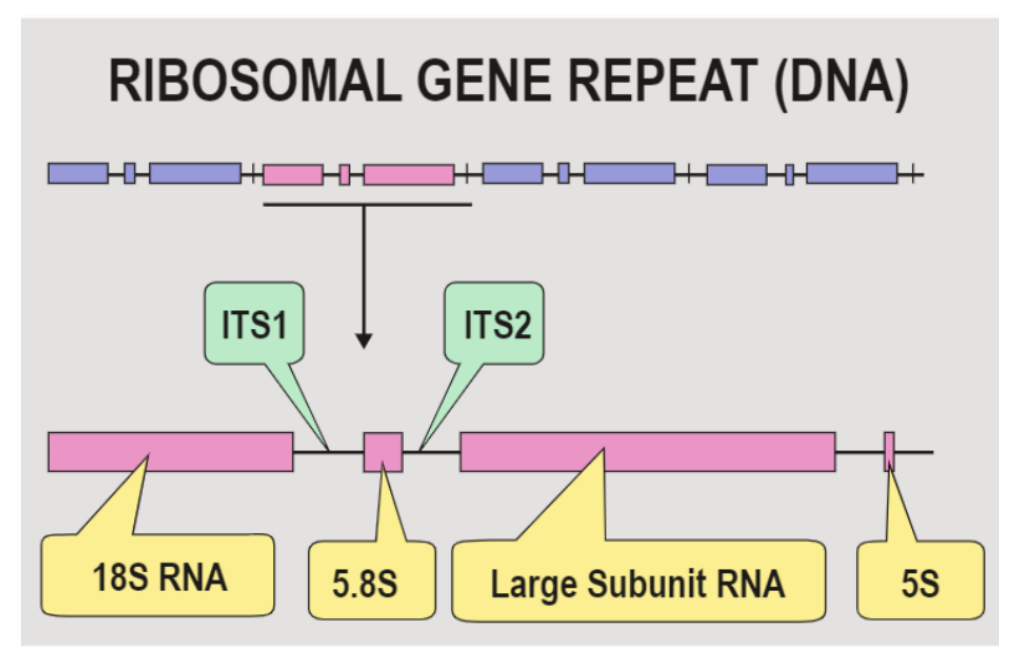

Figure 2. ITS regions together with ribosomal subunits (Choudhary et al., 2015)

ITS due to more variation properties than ribosomal sequences have been commonly used for molecular markers to figure out phylogenetic analysis and/or identification of bacteria, plant and animal strains and/or species (Lee et al., 2017; Rocha et al., 2019; Ali et al., 2019; 
Fazeli-Nasab et al., 2020). Pourahmad et al. (2019) performed sequence analysis of the mycobacterial 16S-23S ITS region to determine aquatic mycobacteria species, reporting effectiveness of this marker. In another study, Yu et al. (2020) evaluated the species specificity of ITS. For this purpose, they improved a determination method based on 500 ITS sequences. They concluded that the accuracy ratio of this procedure was $99.3 \%$ and $100 \%$ for species level and genus level, respectively in Streptococcus. A similar study was performed in a fungal community. Deng et al. (2020) investigated the specificity of ITS sequences by using in silico and even experimental analyses. They suggested that primer selection could affect the finding of amplicon-based metabarcoding studies due to different taxonomic levels.

\section{IRAP (Inter Retrotransposon Amplified Polymorphism)}

IRAP is a retrotransposon-based molecular marker technique, using primers face outwards from LTR (Long Terminal Repeats) regions. Single primer or different primers depending on LTR sequences are used for amplifying genomic DNA regions between retrotransposons (Kalendar and Schulman, 2006) (Figure 3). In this technique, high polymorphism levels could detect without DNA digestion, ligations or probe hybridisation.
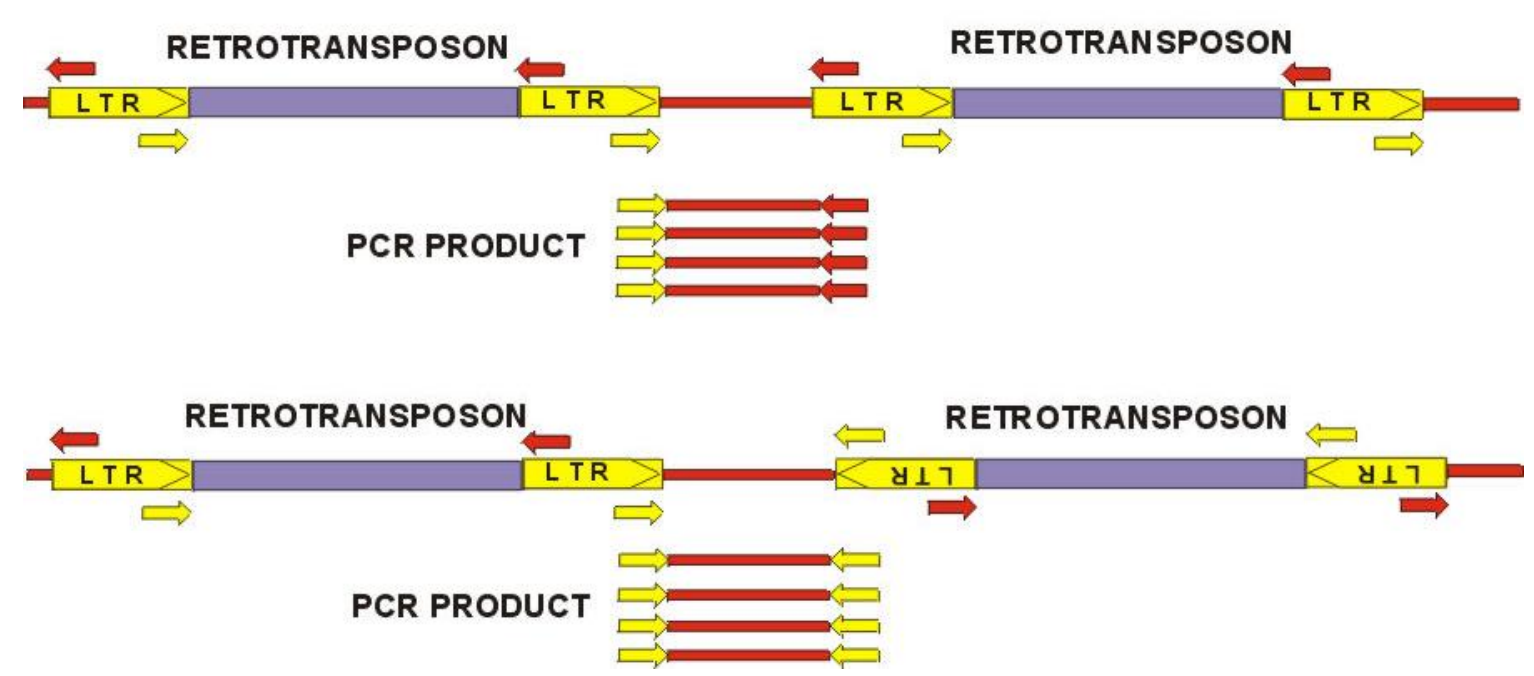

Figure 3. Procedure of IRAP molecular marker

(http://www.biocenter.helsinki.fi/bi/genomedynamics/markers.html)

There are many retrotransposons based molecular markers but IRAP method has been used for several studies to investigate genetic diversity, especially plant species (Noormohammadi et al, 2018; Lancíková and Žiarovská, 2020). Furthermore, there are also different studies 
using combination of two retrotransposon markers: IRAP and REMAP (RetrotransposonMicrosatellite Amplified Polymorphisms). One of them was carried out by Holasou et al. (2019) to evaluate genetic diversity in wheat (Triticum aestivum L.). They reported that both methods produced highly polymorphic bands in samples. Shingote et al. (2019) also identified that IRAP system was superior to ISSR in terms of marker in terms of index, resolving power and polymorphic loci per assay.

In addition to REMAP and ISSR, SCoT (start codon-targeted) markers together with IRAP has also been used to analyse relationships among samples. Guan et al. (2020) investigate genetic diversity of 268 Diospyros accessions from different regions in China, determining 90 and 97 polymorphic alleles from nine SCoT and nine IRAP markers. Shehata et al. (2020) performed different study in both yeast (Saccharomyces cerevisiae L.) and barley (Hordeum vulgare L.) by using IRAP and SCoT. Obtaining findings indicated that different band patterns observed between control and salt treatments, and even the high levels of salinity could cause new retrotranspositions.

\section{SSR (Simple Sequence Repeats)}

Genomes consist of repetitive elements classified as interspersed repeats and tandem repeats depending on distribution SSR (microsatellites) with units of 1 to 6-10 bp are subclass of microsatellites in tandem repeats (Dumbovic et al., 2017) (Figure 4). There are two main approaches to develop SRR primers: i. Analysing known SSR primers already improved for related species and ii. production of genomic library and improving SSRs b using NGS technologies (Csencsics et al., 2010). In addition to genomic analyses, de novo transcriptome sequencing (RNA-Seq) is also reliable approach for SSR development in different species, (Taheri et al., 2018).

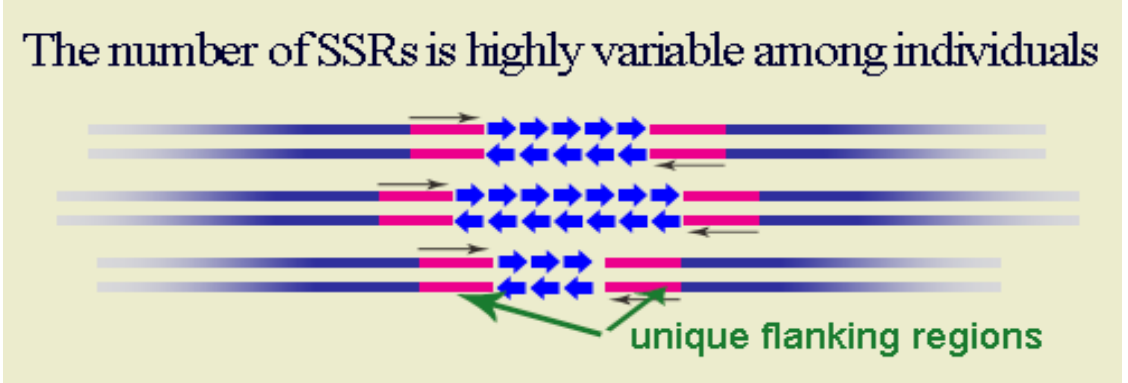

Figure 4. SSR markers (https://www.ncbi.nlm.nih.gov/probe/docs/techsts) 
SSR markers have also been widely used in genetic diversity studies especially in plants such as rice (Jasim Aljumaili et al., 2018), walnut (Bernard et al., 2018), torch ginger (Ismail et al., 2019), maize (Adu et al., 2019), Norway spruce (Bínová et al., 2020) and chickpea (Asadi et al., 2020). Moreover, development of EST-SSR markers have been also studied in Indian mulberry (Thumilan et al., 2016), Lycium barbarum (Chen et al., 2017), Bletilla striata (Xu et al., 2018), Lilium (Biswas et al., 2018), Chinese Hawthorn (Ma et al., 2019) and opium poppy (Vašek et al., 2020). In addition to plants, these markers are also used for animal (Li et al., 2020; Silva Junior et al., 2020) and human (Pai et al., 2016).

\section{VNTR (Variable Number Tandem Repeats)}

VNTR also known as minisatellites are a member of repetitive DNA sequences dispersed in genome. They organised as tandem repeat units of a 10-60 base motif, flanked by conserved DNA restriction sites (Figure 5). These sequences show variations in length (number of repeats) among individuals (Singh et al., 2008).

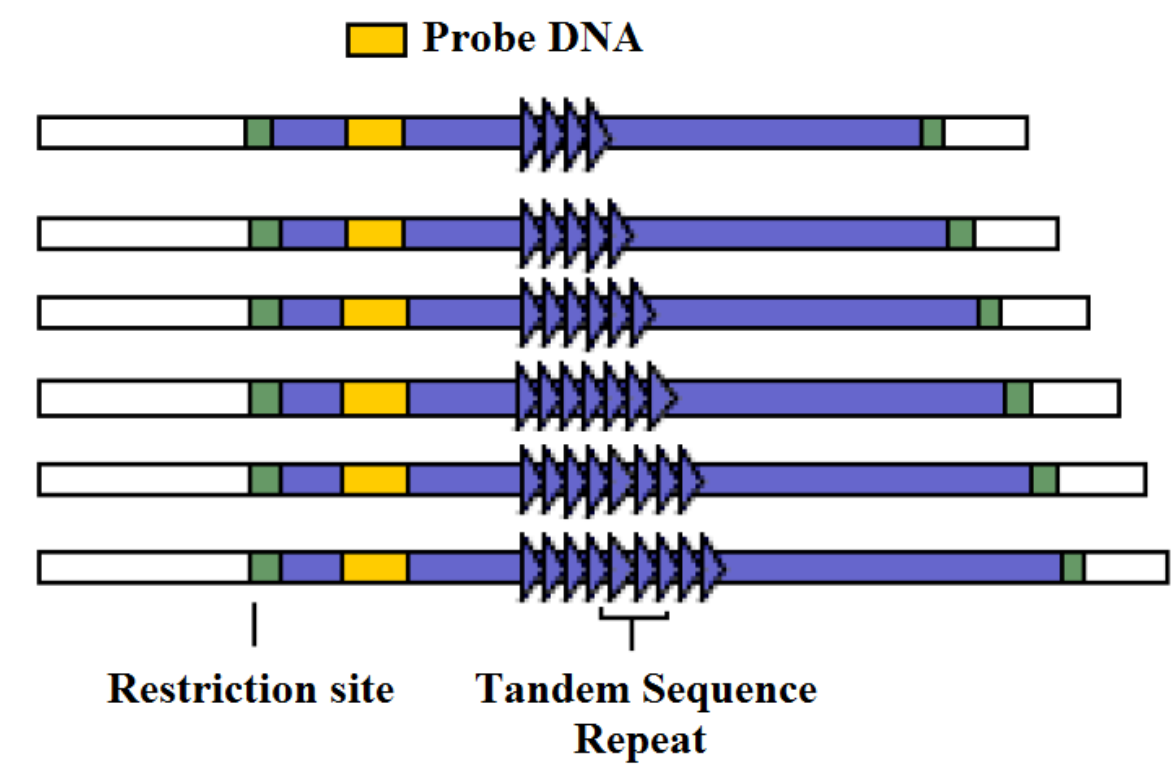

Figure 5. SSR markers (https://www.ncbi.nlm.nih.gov/probe/docs/techsts)

VNTRs are an important source of RFLP (Restriction Fragment Length Polymorphism) markers in linkage analysis (mapping) of genomes. Similar to other molecular markers, VNTR method has been also utilised for genetic diversity and understand evolutionary relationships between species (Apablaza et al., 2015; Hu et al., 2015; Ghielmetti et al., 2017). The versatility of this marker allows it to be easily used in different organisms. Mathema et al. 
(2019) evaluated six microsatellite markers were developed and tested in $37 P$. malariae isolates, concluding sufficient heterozygosity among samples. Furthermore, Sneideris et al. (2019) reported high genetic diversity as a result of VNTR tests on F. graminearum isolates. Najar-Peerayeh et al. (2019) studied with other basteria species, A. baumannii, determining high level of polymorphism similar to Sneideris et al. (2019).

\section{SNP (Single Nucleotide Polymorphism)}

Single nucleotide polymorphisms (SNP) are found almost all living things. If more than $1 \%$ of a population not carry a same nucleotide at a specific DNA position, then this variation can be named as a SNP. SNPs can occur once every 1000 bases or so. Not only a SNP is a nucleotide difference in DNA but also causes genetic polymorphisms among individuals and even populations (Perkel, 2008) (Figure 6).

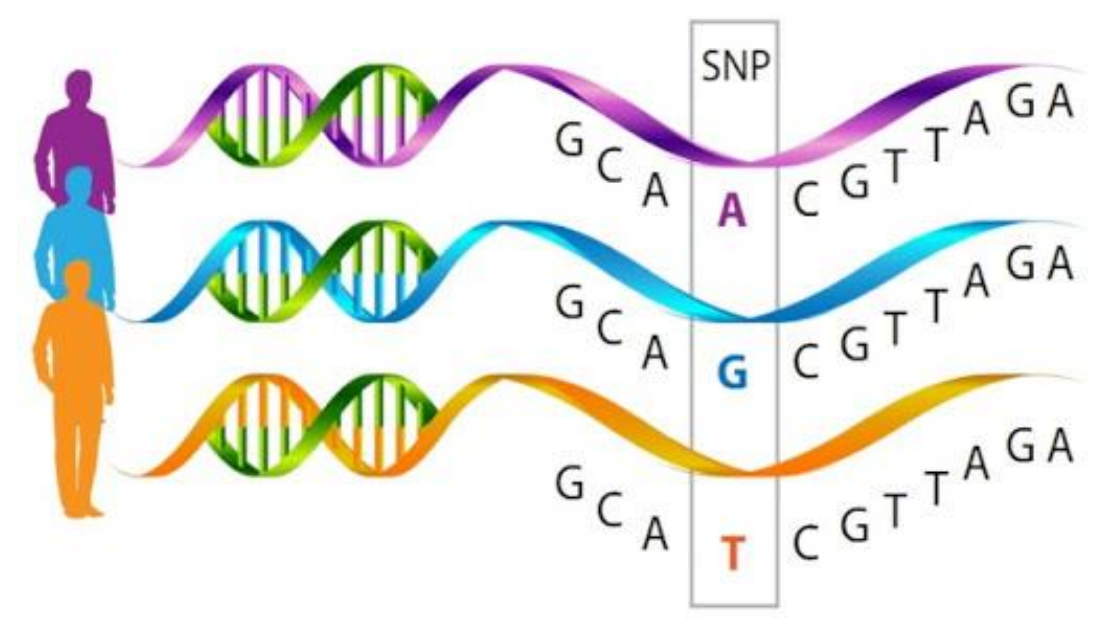

Figure 6. SNPs are DNA differences found in a specific location (https://genetics.thetech.org/ask-a-geneticist)

SNPs are used to identify gene or genes responsible for traits (Li et al., 2020; Ayala-Usma et al., 2020). In human, animal and plant genomes, there are many studies in terms of SNPs analyses. Among them, Kuhn et al. (2019) investigated biallelic SNP markers in mango germplasm. Zafar et al. (2020) studied with the relationships between oleic acid and SNPs in Brassica napus. Moreover, Amanullah et al. (2020) developed SNPs based cleaved amplified polymorphism sequence (CAPS) markers in melon. In a different analysis, Zhao et al. (2019) studied with meat from yak and cattle, identifying higher polymorphism in the cattle population and monomorphism in the yak population. Fatai et al. (2020) performed in silico 
analyses to identify functional and structural effects of inhibin A gene which is a growth factor and relationships between this gene and SNPs. In addition to correlating trait and SNPs, some SNPs can also be associated with certain diseases (Liu et al., 2020; Shibeshi et al., 2020).

\section{CAPS (Cleaved Amplified Polymorphic Sequences)}

CAPS are DNA fragments amplified by PCR using specific primers, then digestion of these amplicons with a restriction enzyme. Length polymorphisms as a result of variation in restriction sites are determined by gel electrophoresis (Figure 7). Therefore, this technique is also referred to PCR-Restriction Fragment Length Polymorphism (PCR-RFLP) (Singh et al., 2008).

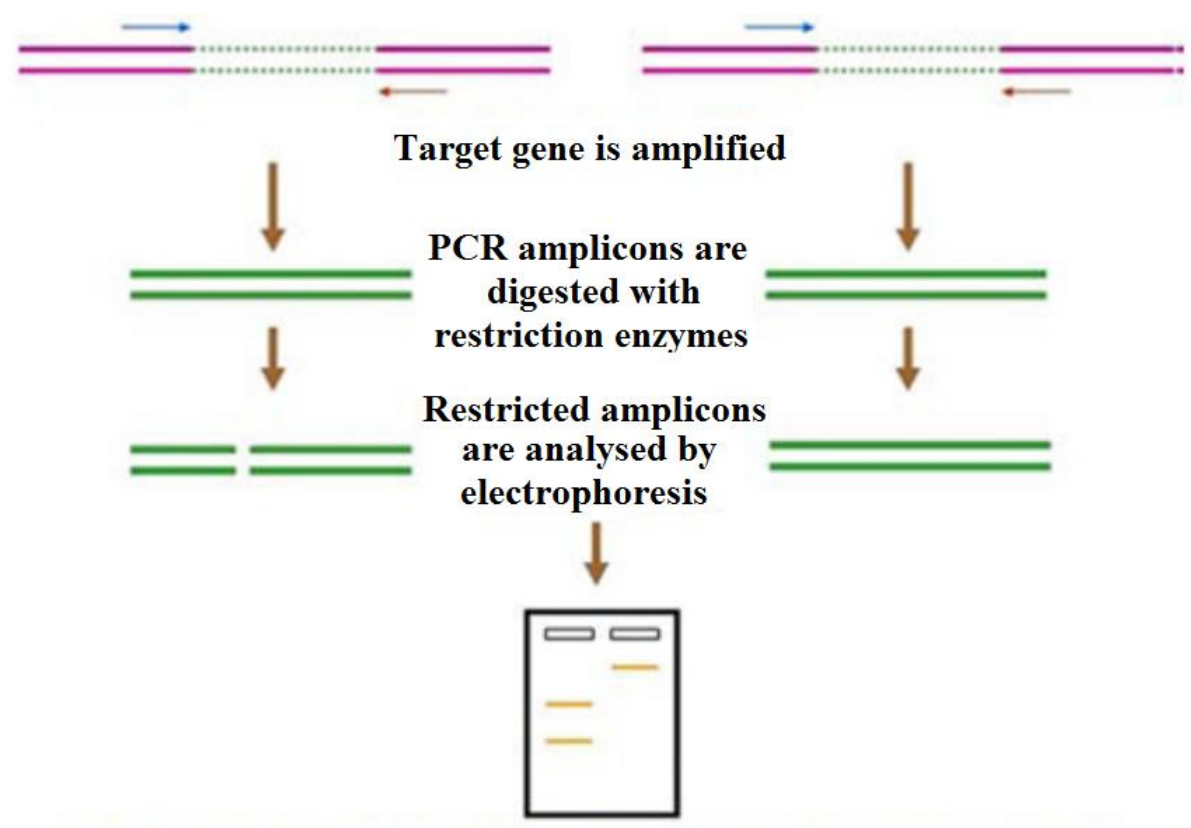

Presence or absence of restriction site helps in differentiation of alleles

Figure 7. Procedures of CAPS technique (Agarwal et al., 2008)

Polymorphisms analyses by using CAPS markers can be used for analysing structural properties (Babu et al., 2017), biotic/abiotic stress (Hubhachen et al., 2020) in addition to genetic diversity and molecular breeding (Kawahara et al., 2020). In one study, Gunaydin and Kafkas (2017) characterised strawberry varieties by using SSR and CAPS markers. They suggested that SSR was considered to be better than CAPS in terms of polymorphism rates. 
Amanullah et al. (2020) combined SNP-CAPS markers to investigate in Cucumis melo L, identifying 7 QTLs for melon ovary traits.

\section{SCoT (Start Codon Targeted Polymorphism)}

SCoT is depended on short conserved region in genes surrounding the ATG translation start (or initiation) codon. Therefore, primers are designed according to the short conserved region flanking the ATG start codon (Figure 8). Amplicons are evaluated by standard gel electrophoresis with agarose gels (Collard and Mackill, 2009).

\section{GENOTYPE \#1}
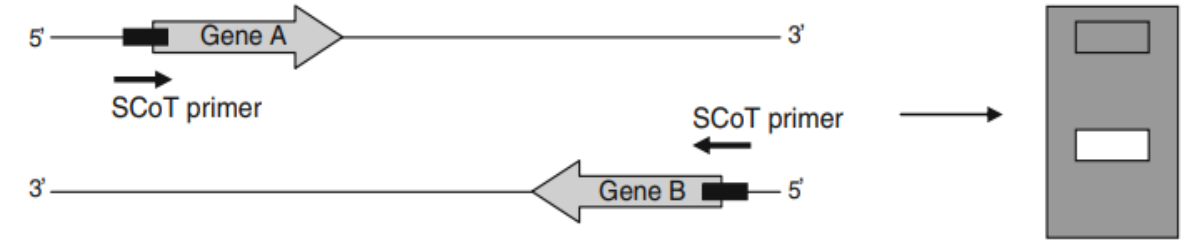

GENOTYPE \#2

\section{PRESENT}
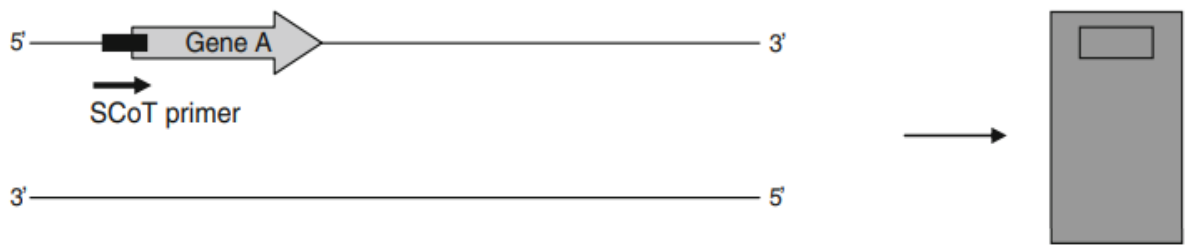

ABSENT

Figure 8. Principle of SCoT analysis (Collard and Mackill, 2009)

Similar to other molecular markers, SCoT could be successfully practised for genetic diversity (Vivodík et al., 2019; Vanijajiva et al., 2020; Xiao et al., 2020). In some studies, SCoT markers were combined with other molecular markers. Etminan et al. (2016) investigated SCoT and ISSR markers together to analyse durum wheat genotypes. In another study, Shekhawat et al. (2018) used SCoT and CBDP (CAAT-box derived polymorphism) markers for Prosopis cineraria. Similarly, Gholamian et al. (2019) also studied with T. urartu by using SCoT and CBDP markers. El-Fiki and Adly combined RAPD and SCoT markers to characterise potato cultivars. 


\section{SSCP (Single Strand Conformational Polymorphism)}

SSCP is based on the electrophoretic mobility of a single-stranded DNA molecule in a non-denaturing gel. This conformational difference depends on the length of strand, sequence, location and number of base pairs (Gasser et al., 2006) (Figure 9).

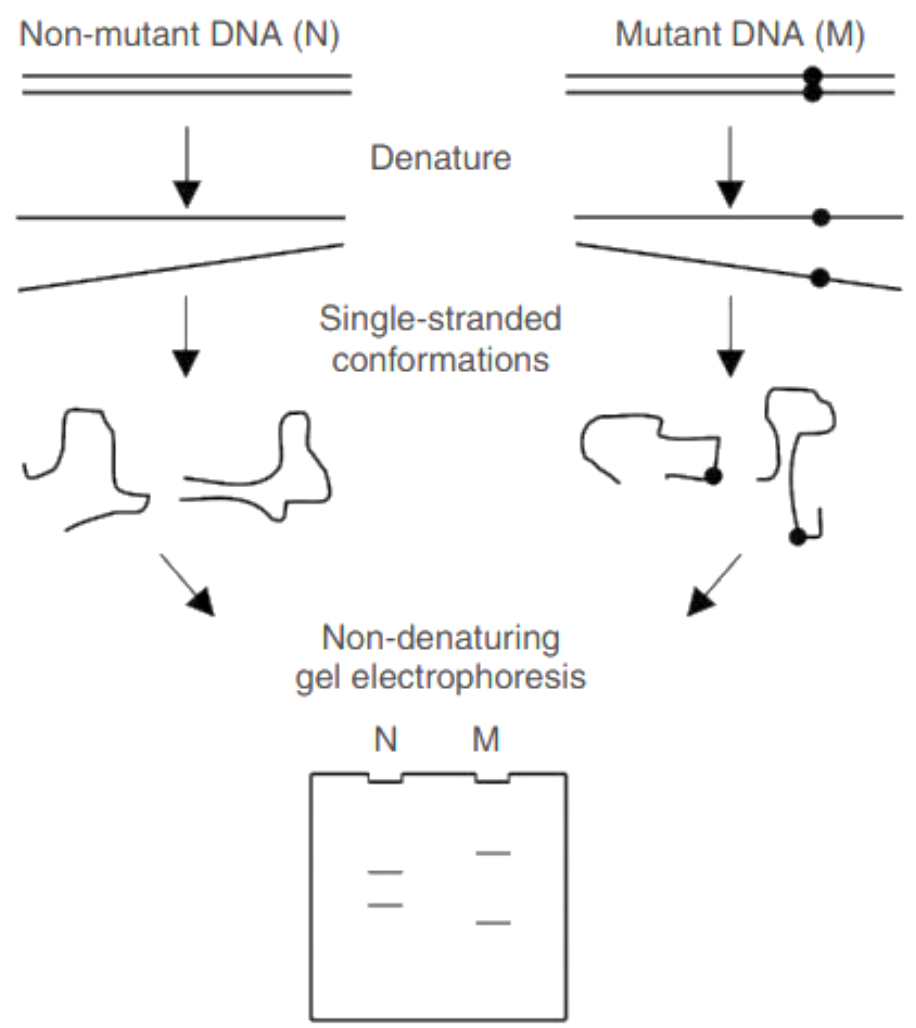

Figure 9. The principle of SSCP analysis. Dot indicates point mutation cause single-strand conformations (Gasser et al., 2006)

Youssef and Shalaby (2016) studied with Citrus Tristeza Virus (CTV), an important virus for citrus, to characterise populations of CTV and id determine haplotypes in populations by using SSCP marker. Zheng et al. (2016) also screened CRISRP-Cas9-mediated targeted mutagenesis in rice via SSCP application. They determined small indels and multiple mutants. In another study, Tchouomene-Labou et al. (2020) used SSCP technique to explore genetic differentiation, gene flow, demographic history and phylogenetic relationship in mitochondrial genes of Glossina palpalis palpalis populations. 


\section{Conclusion}

Each marker system has advantages and disadvantages. Therefore, many studies have been performed by using combination of different markers to eliminate disadvantages. Moreover, the continuous development of molecular markers with advancements in sequencing technologies has provided a powerful tool in biotechnological research. It is important to know procedures and applications of molecular markers to improve existing markers and production of new markers.

\section{References}

Ali, F.S., Ismail, M., Mamoon, A. 2019. Comparative molecular identification of genus Dicentrarchus using mitochondrial genes and internal transcribed spacer region, Egyptian Journal of Aquatic Biology and Fisheries, 23(3): 371-384.

Amanullah, S., Saroj, A., Osae, B. A., Liu, S., Liu, H. et al. 2020. Detection of putative QTL regions associated with ovary traits in melon using SNP-CAPS markers, Scientia Horticulturae, 270: 109445.

Adu, G.B., Awuku, F.J., Amegbor, I.K., Haruna, A., Manigben, K.A. et al. 2019. Genetic characterization and population structure of maize populations using SSR markers, Annals of Agricultural Sciences, 64(1): 47-54.

Agarwal, M., Shirvastava, N., Padh, H. 2008. Advances in molecular marker techniques and their applications in plant sciences, Plant Cell Reports, 27: 617-631.

Apablaza, P., Brevik, Ø. J., Mjøs, S., Valdebenito, S., Ilardi, P. et al. 2015. Variable Number of Tandem Repeats (VNTR) analysis of Flavobacterium psychrophilum from salmonids in Chile and Norway, BMC Veterinary Research, 11(1): 150.

Asadi, A., Ebrahimi, A., Rashidi-Monfared, S., Basiri, M., Akbari-Afjani, J. 2020. Comprehensive functional analysis and mapping of SSR markers in the chickpea genome (Cicer arietinum L.), Computational Biology and Chemistry, 84: 107169.

Ayala-Usma, D.A., Danies, G., Myers, K., Bond, M.O., Romero-Navarro, J.A. et al. 2020. Genome-wide association study identifies single nucleotide polymorphism markers associated with mycelial growth (at 15,20 , and $25^{\circ} \mathrm{C}$ ), mefenoxam resistance, and mating type in Phytophthora infestans, Phytopathology, 110(4): 822-833.

Babu, B.K., Mathur, R.K., Kumar, P.N., Ramajayam, D., Ravichandran, G. et al. 2017. Development, identification and validation of CAPS marker for SHELL trait which governs dura, pisifera and tenera fruit forms in oil palm (Elaeis guineensis Jacq.), PLoS ONE, 12(2): e0171933.

Bernard, A., Barreneche, T., Lheureux, F., Dirlewanger, E. 2018. Analysis of genetic diversity and structure in a worldwide walnut (Juglans regia L.) germplasm using SSR markers, PLoS ONE, 13(11): e0208021.

Bínová, Z., Korecký, J., Dvořák, J., Bílý, J., Zádrapová, D. et al. 2020. Genetic structure of norway spruce ecotypes studied by SSR markers, Forests, 11(1): 110.

Biswas, M.K., Nath, U.K., Howlader, J., Bagchi, M., Natarajan, S. et al. 2018. Exploration and exploitation of novel SSR markers for candidate transcription factor genes in Lilium species, Genes, 9: 97. 
Cao, J., Zhou, Z., Tu, J., Cheng, S., Yao, J. et al. 2019. Genetic diversity and population structure analysis of sand pear (Pyrus pyrifolia) 'Nakai 'varieties using SSR and AFLP markers, Notulae Botanicae Horti Agrobotanici Cluj-Napoca, 47(3): 970-979.

Chen, C.L., Xu, M.L., Wang, C.P., Qiao, G.X., Wang, W.W. et al. 2017. Characterization of the Lycium barbarum fruit transcriptome and development of EST-SSR markers, PLoS ONE, 12: e0187738.

Choudhary, K., Verma, A.K., Swaroop, S., Agrawal, N. 2015. A review on the molecular characterization of digenean parasites using molecular markers with special reference to ITS region, Helminthologia, 52(3): 167-187.

Collard, B.C., Mackill, D.J. 2009. Start codon targeted (SCoT) polymorphism: a simple, novel DNA marker technique for generating gene-targeted markers in plants, Plant Molecular Biology Reporter, 27(1): 86-93.

Csencsics, D., Brodbeck, S., Holderegger, R. 2010. Cost-Effective, species-specific microsatellite development for the endangered dwarf bulrush (Typha minima) using nextgeneration sequencing technology, Journal of Heredity, 101: 789-793.

Dumbovic, G., Forcales, S.V., Perucho, M. 2017. Emerging roles of macrosatellite repeats in genome organization and disease development, Epigenetics, 12(7): 515-526.

El-Fiki, A., Adly, M. 2019. Genetic variation and molecular characterization in some potato cultivars using random amplified polymorphic DNA and start codon targeted markers, Egyptian Journal of Biotechnology, 59.

Etminan, A., Pour-Aboughadareh, A., Mohammadi, R., Ahmadi-Rad, A., Noori, A. et al. 2016. Applicability of start codon targeted (SCoT) and inter-simple sequence repeat (ISSR) markers for genetic diversity analysis in durum wheat genotypes, Biotechnology \& Biotechnological Equipment, 30(6): 1075-1081.

Fatai, R.B., Akinyemi, M.O., Osaiyuwu, O.H. 2020. In silico analysis of single nucleotide polymorphism in inha gene of sheep and goats, Biotechnology Journal International, 1221.

Fazeli-Nasab, B., Sayyed, R.Z., Farsi, M., Ansari, S., El-Enshasy, H.A. 2020. Genetic assessment of the internal transcribed spacer region (ITS1. 2) in Mangifera indica L. landraces, Physiology and Molecular Biology of Plants, 26(1): 107-117.

Gasser, R.B., Hu, M., Chilton, N.B., Campbell, B.E., Jex, A.J. et al. 2006. Single-strand conformation polymorphism (SSCP) for the analysis of genetic variation, Nature Protocols, 1(6): 3121.

Günaydın, S., Kafkas, S. Characterization of strawberry cultivars by SSR and CAPS Markers. VIII International Strawberry Symposium, 13-17 August 2016, p. 171-178.

Ghielmetti, G., Scherrer, S., Friedel, U., Frei, D., Suter, D. et al. 2017. Epidemiological tracing of bovine tuberculosis in Switzerland, multilocus variable number of tandem repeat analysis of Mycobacterium bovis and Mycobacterium caprae, PLoS ONE, 12(2): e0172474.

Gholamian, F., Etminan, A., Changizi, M., Khaghani, S., Gomarian, M. 2019. Assessment of genetic diversity in Triticum urartu Thumanjan ex Gandilyan accessions using start codon targeted polymorphism (SCoT) and CAAT-box derived polymorphism (CBDP) markers, Biotechnology \& Biotechnological Equipment, 33(1): 1653-1662.

Grover, A., Sharma, P.C. 2016. Development and use of molecular markers: past and present, Critical Reviews in Biotechnology, 36(2): 290-302.

Guan, C., Chachar, S., Zhang, P., Hu, C., Wang, R. et al. 2020. Inter-and intra-specific genetic diversity in Diospyros using SCoT and IRAP markers, Horticultural Plant Journal, 6(2): 71-80. 
Hadipour, M., Kazemitabar, S.K., Yaghini, H., Dayani, S. 2020. Genetic diversity and species differentiation of medicinal plant Persian Poppy (Papaver bracteatum L.) using AFLP and ISSR markers, Ecological Genetics and Genomics, 100058.

Holasou, H.A., Rahmati, F., Rahmani, F., Imani, M., Talebzadeh, Z. 2019. Elucidate genetic diversity and population structure of bread wheat (Triticum aestivum L.) cultivars using IRAP and REMAP markers, Journal of Crop Science and Biotechnology, 22(2): 139-151.

Hu, Y., Li, B.Q., da Jin, Z., He, L.H., Tao, X.X. et al. 2015. Identification of VariableNumber Tandem-Repeat (VNTR) sequences in Acinetobacter pittii and development of an optimized multiple-locus VNTR analysis typing scheme, Biomedical and Environmental Sciences, 28(12): 855-63.

Hubhachen, Z., Jiang, H., Schlipalius, D., Park, Y., Guedes, R.N. et al. 2020. A CAPS marker for determination of strong phosphine resistance in Tribolium castaneum from Brazil, Journal of Pest Science, 93(1): 127-134.

Imwong, M., Mathema, V. B., Nakeesathit, S., Pagornrat, W., Smithuis, F. et al. 2019. Polymorphic markers for identification of parasite population in Plasmodium malariae, Malaria Journal, 19: 48.

Ismail, N.A., Rafii, M.Y., Mahmud, T.M.M., Hanafi, M.M., Miah, G. 2019. Genetic diversity of torch ginger (Etlingera elatior) germplasm revealed by ISSR and SSR markers, BioMed Research International, doi: 10.1155/2019/5904804.

Jasim Aljumaili, S., Rafii, M. Y., Latif, M. A., Sakimin, S. Z., Arolu, I. W. et al. 2018. Genetic diversity of aromatic rice germplasm revealed by SSR markers, BioMed Research International, doi: 10.1155/2018/7658032.

Kalendar, R., Schulman, A. 2006. IRAP and REMAP for retrotransposon-based genotyping fingerprinting, Nature Protocols, 1(5): 2478-2484.

Kawahara, Y., Endo, T., Omura, M., Teramoto, Y., Itoh, T. et al. 2020. Mikan Genome Database (MiGD): integrated database of genome annotation, genomic diversity, and CAPS marker information for mandarin molecular breeding, Breeding Science, doi: 10.1270/jsbbs. 19097.

Kuhn, D.N., Dillon, N., Bally, I., Groh, A., Rahaman, J. et al. 2019. Estimation of genetic diversity and relatedness in a mango germplasm collection using SNP markers and a simplified visual analysis method, Scientia Horticulturae, 252: 156-168.

Lancíková, V., Žiarovská, J. 2020. Inter-retrotransposon amplified polymorphism markers revealed long terminal repeat retrotransposon insertion polymorphism in flax cultivated on the experimental fields around Chernobyl, Journal of Environmental Science and Health, Part A Toxic/Hazardous Substances and Environmental Engineering, 55(8): 957-963.

Lee, S.Y., Mohamed, R., Faridah-Hanum, I., Lamasudin, D.U. 2017. Utilization of the internal transcribed spacer (ITS) DNA sequence to trace the geographical sources of Aquilaria malaccensis Lam. Populations, Plant Genetic Resources, 16(2): 103-111.

Li, J., Hou, L., Sun, Y., Xing, J., Jiang, Y. et al. 2020. Single nucleotide polymorphism rs737028527 (G> A) affect miR-1b-3p and effects on chicken egg-laying traits, Animal Reproduction Science, 106476.

Li, S., Deng, Y., Wang, Z., Zhang, Z., Kong, X. et al. 2020. Exploring the accuracy of amplicon-based internal transcribed spacer markers for a fungal community, Molecular Ecology Resources, 20(1): 170-184.

Li, X., Tang, Y., Zhang, R., Tian, F., Zhao, K. 2020. Characterization and development of SSR markers of schizothoracine fish (Cypriniformes: Cyprinidae) based on SLAF-seq Technique, Journal of Applied Ichthyology, doi: 10.1111/jai.14032.

Liu, Z., Yin, X., Mai, H., Li, G., Lin, Z. et al. 2020. SCD rs41290540 single-nucleotide polymorphism modifies miR-498 binding and is associated with a decreased risk of coronary artery disease, Molecular Genetics \& Genomic Medicine, 8(3): e1136. 
Ma, S.L.Y., Dong, W.S., Lyu, T., Lyu, Y.M. 2019. An RNA sequencing transcriptome analysis and development of EST-SSR markers in Chinese hawthorn through Illumina sequencing, Forests, 10: 82.

Moya-Hernández, A., Bosquez-Molina, E., Serrato-Díaz, A., Blancas-Flores, G., AlarcónAguilar, F.J. 2018. Analysis of genetic diversity of Cucurbita ficifolia Bouché from different regions of Mexico, using AFLP markers and study of its hypoglycemic effect in mice, South African Journal of Botany, 116: 110-115.

Nadeem, M. A., Nawaz, M. A., Shahid, M. Q., Doğan, Y., Comertpay, G. et al. 2018. DNA molecular markers in plant breeding: current status and recent advancements in genomic selection and genome editing, Biotechnology \& Biotechnological Equipment, 32(2): 261285.

Najar-Peerayeh, S., Karmostaji, A. 2019. Evaluation of multilocus Variable-Number TandemRepeat (MLVA-8 Orsay) for Typing of carbapenem-resistant Acinetobacter baumannii isolated from patients in Tehran, Iran, Archives of Clinical Infectious Diseases, 14(1): e64402s

Noormohammadi, Z., Ibrahim-Khalili, N., Sheidai, M., Alishah, O. 2018. Genetic fingerprinting of diploid and tetraploid cotton cultivars by retrotransposon-based markers, The Nucleus, 61(2): 137-143.

Ovesná, J., Russo, D., Frescura, D., Cusimamani, E.F., Svobodova, E. et al. 2018. Assessment of genetic diversity of Smallanthus sonchifolius (Poepp. \& Endl.) h. Robinson landraces by using AFLP markers, Genetika, 50(3): 803-816.

Pai, T.W., Chen, C. M. 2016. SSRs as genetic markers in the human genome and their observable relationship to hereditary diseases, Biomarkers in Medicine, 10(6): 563-566.

Paun, O., Schönswetter, P. 2012. Amplified fragment length polymorphism: an invaluable fingerprinting technique for genomic, transcriptomic, and epigenetic studies. In: Sucher, N.J., Hennell, J.R., Carles, M.C. (Eds.). Plant DNA Fingerprinting and Barcoding. pp. 7587, Humana Press.

Perkel, J. 2008. SNP genotyping: six technologies that keyed a revolution, Nature Methods, 5(5): 447-453.

Pourahmad, F., Adams, A., Thompson, K.D., Richards, R.H. 2019. Identification of aquatic mycobacteria based on sequence analysis of the 16S-23S rRNA internal transcribed spacer region, Journal of Medical Microbiology, 68(2): 221-229.

Rocha, G.M., Martinelli, A.B., Utz, L.R.P., Fernandes, L.F.L. 2019. Using internal transcribed spacers for Calanoida (Crustacea, Copepoda) species identification, Marine Biodiversity, 49(3): 1565-1571.

Shehata, M.M., Fahmy, E.M., Mohamed Badawy, F., Mostafa Kamal Sayed, L. 2020. Measuring of the alteration of retrotransposition in the response of salinity stress using IRAP and SCoT markers, Arab Universities Journal of Agricultural Sciences, doi: s10.21608/ajs.2019.18888.1107

Shekhawat, J.K., Rai, M.K., Shekhawat, N.S., Kataria, V. 2018. Exploring genetic variability in Prosopis cineraria using two gene targeted CAAT box-derived polymorphism (CBDP) and start codon targeted (SCoT) polymorphism markers, Molecular Biology Reports, 45(6): 2359-2367.

Shibeshi, S., Adetimirin, V.O., Kumar, L., Abebe, M., Gedil, M. 2020. Verification of single nucleotide polymorphism (SNP) markers associated with maize (Zea mays. L) streak virus resistance in early generation maize lines, International Journal of Genetics and Molecular Biology, 12(1): 36-45. 
Shingote, P.R., Mithra, S.A., Sharma, P., Devanna, N.B., Arora, K. et al. 2019. LTR retrotransposons and highly informative ISSRs in combination are potential markers for genetic fidelity testing of tissue culture-raised plants in sugarcane, Molecular Breeding, 39(2): 25.

Silva Junior, M.S.F.S.D., Borges, A.A.D.S., Santos, S.R.N., Moura, V.G.D., Silvana, G.R.D. et al. 2020. SSR and ISSR markers in assessing genetic diversity in Gallus gallus domesticus: a quantitative analysis of scientific production, Ciência Rural, 50(7): e20190401.

Singh, R.K., Mishra, G.P., Thakur, A.K., Singh, S.B. 2008. Molecular markers in plants. In: Singh, R.K., Singh, R., Ye, G.Y., Selvi, A., Rao, G.P. (Eds.). Molecular Plant Breeding: Principle, Method And Application, Studium Press LLC, Houston, pp. 35-78.

Sneideris, D., Ivanauskas, A., Suproniene, S., Kadziene, G., Sakalauskas, S. 2019. Genetic diversity of Fusarium graminearum isolated from weeds, European Journal of Plant Pathology, 153(2): 639-643.

Taheri, S., Lee Abdullah, T., Yusop, M., Hanafi, M., Sahebi, M. et al. 2018. Mining and development of novel SSR markers using Next Generation Sequencing (NGS) Data in Plants, Molecules, 23(2): 399.

Tchouomene-Labou, J., Melachio-Tanekou, T.T., Simo, G., Kaba, D., Ravel, S. et al. 2020. Single-strand conformation polymorphism (SSCP) of mitochondrial genes helps to estimate genetic differentiation, demographic parameters and phylogeny of Glossina palpalis palpalis populations from West and Central Africa, Infection, Genetics and Evolution, 104303.

Thumilan, B.M., Sajeevan, R.S., Madhuri, B.J.T., Nataraja, K.N., Sreeman, S.M. 2016. Development and characterization of genic SSR markers from Indian mulberry transcriptome and their transferability to related species of Moraceae, PLoS ONE, 11: $\mathrm{e} 0162909$.

Vanijajiva, O. 2020. Start codon targeted (SCoT) polymorphism reveals genetic diversity of Manilkara in Thailand, Biodiversitas Journal of Biological Diversity, 21: 666-673.

Vašek, J., Č́lová, D., Melounová, M., Svoboda, P., Vejl, P. et al. 2020. New EST-SSR markers for individual genotyping of opium poppy cultivars (Papaver somniferum L.), Plants, 9(1): 10.

Vivodík, M., Balážová, Ž., Gálová, Z., Petrovičová, L. 2019. Start codon targeted polymorphism for evaluation of functional genetic variation and relationships in cultivated castor (Ricinus communis L.) genotypes, Genetika, 51(1): 137-146.

Vuylsteke, M., Peleman, J.D., Van Eijk, M.J. 2007. AFLP technology for DNA fingerprinting, Nature Protocols, 2(6): 1387.

Wei, N.W.V., Wallace, C.C., Dai, C.F., Pillay, K.M., Chen, C.A. 2006. Analyses of the ribosomal Internal Transcribed Spacers (ITS) and $5.8 \mathrm{~S}$ gene indicate that extremely high rDNA heterogeneity is a unique feature in the scleractinian coral genus Acropora (Scleractinia; Acroporidae), Zoological Studies, 45(3): 404.

Xiao, P., Liu, H., Wang, D., Tang, W., Yang, H. et al. 2020. Assessment of genetic diversity in Camellia oleifera Abel. accessions using inter-simple sequence repeat (ISSR) and start codon targeted (SCoT) polymorphic markers, Genetic Resources and Crop Evolution, 67: $1115-1124$.

Xu, D., Chen, H., Aci, M., Pan, Y., Shangguan, Y. et al. 2018. De novo assembly, characterization and development of EST-SSRs from Bletilla striata transcriptomes profiled throughout the whole growing period, PLoS ONE, 13: e0205954.

Youssef, S.A., Shalaby, A.A. 2016. Single-Strand Conformation Polymorphism (SSCP) and nucleotide sequence analysis of Citrus tristeza virus in Egypt, International Journal of Advanced Research in Biological Science, 3(5): 84-92. 
Yu, J., Zhou, T., Zhu, B., Wei, Y., Li, X. et al. 2020. Species-specific identification of Streptococcus based on DNA marker in 16S-23S rDNA internal transcribed spacer, Current Microbiology, 77, 1569-1579.

Zafar, S., Tang, M.Q., Wang, Y.K., Sarwar, R., Liu, S.Y. et al. 2020. Candidate genesassociation study to identify loci related to oleic acid in Brassica napus using SNP markers and their heterologous expression in yeast, Plant Physiology and Biochemistry, 146: 294302.

Zhao, J., Xu, Z., Chen, A., You, X., Zhao, Y. et al. 2019. Identification of meat from yak and cattle using SNP markers with integrated allele-specific polymerase chain reactioncapillary electrophoresis method, Meat Science, 148: 120-126.

Zheng, X., Yang, S., Zhang, D., Zhong, Z., Tang, X. et al. 2016. Effective screen of CRISPR/Cas9-induced mutants in rice by single-strand conformation polymorphism, Plant Cell Reports, 35(7): 1545-1554. 